\title{
Caracterização agronômica e potencial antioxidante de frutos de clones de aceroleira ${ }^{1}$
}

\author{
Agronomic characterization and antioxidant potential of fruit from clones of the \\ acerola plant
}

\author{
Jonas Cunha Neto ${ }^{2}$, Marcela Cristina Rabelo ${ }^{3}$, Cândida Hermínia Campos de Magalhães Bertini², Gleidson \\ Vieira Marques ${ }^{4}$ e Maria Raquel Alcântara de Miranda ${ }^{3 *}$
}

\begin{abstract}
RESUMO - A acerola é um fruto tropical de grande potencial agronômico e nutricional. A propagação vegetativa da aceroleira é uma vantagem para a obtenção e seleção rápida de clones superiores. Com o objetivo de avaliar clones de aceroleira quanto às características agronômicas e a capacidade antioxidante dos frutos, um experimento foi instalado em blocos ao acaso com 25 tratamentos, três repetições e três plantas por parcela, no Campo Experimental de Paraipaba, CE. Durante três anos, foram avaliados: altura da planta, diâmetro de copa, produção e como parâmetros pós-colheita dos frutos, os antioxidantes enzimáticos e não enzimáticos. Pelos resultados obtidos, conclui-se que o padrão de crescimento em altura apresentado pelos clones é resultado da seleção conduzida entre e dentre as progênies por dois ciclos. Dentre todos os materiais estudados, os 23/2(3), 79/10(9) e 26/5(4) apresentam boas produtividades e conteúdos de vitamina $\mathrm{C}$ e demonstram ter um potencial para a indústria de extração de vitamina C, enquanto, o material 20/4(8) possui boa produtividade e bom desenvolvimento vegetativo, portanto um bom potencial para a produção voltada para o consumo in natura.
\end{abstract}

Palavras-chave: Acerola. Frutos. Melhoramento genético. Vitamina C. Enzimas.

\begin{abstract}
Acerola is a tropical fruit with great agronomic and nutritional potential. Vegetative propagation of acerola plant can be an advantage for a quick selection of superior clones. With the objective of evaluating acerola clones regarding their agronomic characteristics and antioxidant capacity of their fruit, an experiment was set up in a randomised-block design with 25 treatments consisting of three replicates with three plants per plot at the Experimental Station in ParaipabaCeará. For three years the following characteristics were evaluated: plant height, crown diameter and yield and as postharvest parameters of the fruit, enzymatic and non-enzymatic antioxidants. The data shows the pattern of vertical growth displayed by the clones is resultant of a selection carried out with the progeny of two cycles. Among the studied clones, 23/2 (3), 79/10 (9) and 26/5 (4) presented good yield and vitamin C content and therefore, have potential for the industrial extraction of vitamin C, while 20/4 (8) has good yield and vegetative growth besides a high antioxidant enzymatic activity, thereby showing good potential for in natura market.
\end{abstract}

Key words: Acerola. Fruit. Genetic Improvement. Vitamin C. Enzymes.

\footnotetext{
*Autor para correspondência

'Recebido para publicação em 11/05/2010; aprovado em 11/03/2012

Projeto financiado pelo CNPq, Brasil

${ }^{2}$ Departamento. de Fitotecnia/Universidade Federal do Ceará, Caixa postal 12.168, Fortaleza-CE, Brasil, 60.021-970, jonascunha.neto@gmail.com, candida@ufc.br

${ }^{3}$ Departamento de Bioquímica e Biologia Molecular/UFC, Caixa Postal 6.039, Fortaleza-CE, Brasil, 60.455-900, marcelacrabelo@gmail.com, rmiranda@ufc.br

${ }^{4}$ Universidade Federal Rural do Semi-Árido, Campus Angicos, Angicos-RN, Brasil, 59.515-000, gleidson@ufersa.edu.br
} 


\section{INTRODUÇÃO}

A seleção de clones é a maneira mais eficiente para suprir a demanda por variedades de uma espécie economicamente importante com um resultado que pode ser visualizado em curto prazo; e esta tem sido a principal metodologia adotada nos programas de melhoramento da acerola. Por ser a aceroleira uma espécie que pode ser propagada vegetativamente, o genótipo de cada planta pode ser transmitido integralmente através das gerações.

Assim, em 1996, a Embrapa Agroindústria Tropical iniciou um programa de melhoramento da aceroleira cujos objetivos eram aumentar a produtividade e a qualidade de frutos e reduzir os custos em plantios comerciais instalados em diferentes localidades no Estado do Ceará. Nesse programa foram conduzidas simultaneamente duas linhas de pesquisa. $\mathrm{O}$ melhoramento populacional foi conduzido por dois ciclos com a avaliação de 126 progênies, a qual resultou na seleção de 38 plantas e na implantação de um Jardim de Sementes que tem como objetivo fornecer material sexuado para o plantio comercial (PAIVA et al., 2002). Já, o melhoramento clonal constou da obtenção de 151 clones que foram avaliados em experimentos instalados em diferentes locais. Como resultado desse esforço, em 2003, quatro clones de acerola foram lançados para o plantio comercial na região da Chapada do Apodi, no município de Limoeiro do Norte, CE (PAIVA et al., 2003a).

Em geral, os programas de melhoramento são realizados com base na avaliação de características agronômicas da planta e físico-químicas de qualidade dos frutos. Porém, outros parâmetros também vêm sendo avaliados devido uma mudança observada nos hábitos alimentares da população, como a busca por alimentos mais saudáveis que possam trazer benefícios à saúde. Os fitonutrientes antioxidantes como a vitamina $\mathrm{C}$ e os compostos fenólicos são capazes de combater os radicais livres envolvidos nos processos degenerativos celulares e assim, fortalecer o sistema imunológico dos animais (OLSSON et al., 2006). Nesse contexto, se torna importante a seleção de clones de aceroleira cujos frutos apresentam conteúdos ainda mais altos de vitamina $\mathrm{C}$ e de antocianinas.

Além de apresentar valor nutricional para os humanos, os antioxidantes são importantes para a fisiologia pós-colheita dos próprios frutos. Pois, a senescência e o amadurecimento que são caracterizados por alterações que resultam em desorganização estrutural do tecido, têm os radicais livres produzidos no metabolismo respiratório como grandes responsáveis por essas alterações (BHATTACHARJEE, 2005). Segundo Lurie (2003), a perda na habilidade de remover os radicais livres durante o amadurecimento e senescência é influenciada pela queda na atividade de enzimas antioxidantes como dismutase do superóxido (SOD), peroxidase do ascorbato (APX) e catalase (CAT). Assim, o amadurecimento e a senescência de frutos podem ser vistos como fenômenos oxidativos e a seleção de variedades com maior capacidade enzimática antioxidante é uma alternativa para obtenção de frutos que podem ser armazenados por períodos mais longos sem perder seus atributos de qualidade.

Portanto, a capacidade antioxidante do tecido vegetal está associada tanto à atividade de enzimas como ao conteúdo de compostos antioxidantes não enzimáticos como a vitamina $\mathrm{C}$, carotenóides, tocoferol (vitamina E) e os compostos fenólicos como as antocianinas (LEJA; MARECZEC; BEN, 2003). Na última década, a capacidade antioxidante de frutos de várias espécies vem sendo estudada (ARAUJO et al., 2004, KULKARNI; ARADHYA, 2005, LEJA; MARECZEC; BEN, 2003).

O presente trabalho teve por objetivo avaliar o desempenho de 25 clones de aceroleira em relação ao desenvolvimento vegetativo das plantas, à produção e potencial antioxidante dos frutos.

\section{MATERIAL E MÉTODOS}

O experimento foi instalado em dezembro de 2002, no Campo Experimental da Embrapa Agroindústria Tropical, localizado no município de Paraipaba, CE, cujas coordenadas geográficas são latitude $3^{\circ} 28^{\prime} 47^{\prime \prime} \mathrm{S}$, longitude $39^{\circ} 09^{\prime} 47^{\prime \prime} \mathrm{W}$ e altitude de $31 \mathrm{~m}$. Conforme descreve Aguiar et al. (2002), o tipo climático é DrA'a' caracterizado como semiárido, com pequeno ou nenhum excesso hídrico. O solo do local apresenta relevo plano e está classificado como Neossolo quartzarênico.

$\mathrm{O}$ experimento foi instalado no delineamento experimental de blocos ao acaso, com 25 tratamentos (Tabela 1), 3 repetições, 3 plantas por parcela, no espaçamento de 4,0 m entre linhas e 4,0 m entre plantas. Os clones foram obtidos por meio da seleção de plantas em população formada por progênies de acerola no segundo ciclo. Inicialmente, foram selecionadas as progênies mais produtivas e, dentro destas, as plantas com maior produção individual de frutos, seguida da seleção fenotípica das plantas no campo, observando-se a conformação da copa e o estado fitossanitário.

Os tratos culturais foram aplicados de acordo com a recomendação para o plantio comercial da acerola na região. A adubação de fundação das plantas constou de $100 \mathrm{~g}$ de calcário, $260 \mathrm{~g}$ de superfosfato triplo, $50 \mathrm{~g}$ de FTE. Mensalmente por planta, foram aplicados $43 \mathrm{~g}$ de uréia e $117 \mathrm{~g}$ de superfosfato simples, $40 \mathrm{~g}$ de cloreto de potássio enquanto, $8 \mathrm{~g}$ de FTE foram aplicados a cada dois meses. O suprimento de água foi feito por irrigação localizada, com microaspersores alto-compensantes com vazão de $43 \mathrm{~L}$ de água. $\mathrm{h}^{-1}$, sendo irrigadas em média uma hora por dia, nos meses sem precipitação pluviométrica. 
Tabela 1 - Identificação e origem dos clones de aceroleira de segundo ciclo

\begin{tabular}{|c|c|c|}
\hline Número & Clones & Origem \\
\hline 1 & $23 / 2(3)$ & $\begin{array}{c}\text { Planta selecionada na progênie } \\
\text { de } 2^{\circ} \text { ciclo de seleção }\end{array}$ \\
\hline 2 & $68 / 1(9)$ & “" \\
\hline 3 & $75 / 2(7)$ & “ \\
\hline 4 & $79 / 10(9)$ & “" \\
\hline 5 & $8 / 2(3)$ & “ \\
\hline 6 & $87 / 11(7)$ & “ \\
\hline 7 & $66 / 7(5)$ & “ \\
\hline 8 & $66 / 7(6)$ & “ \\
\hline 9 & $79 / 9(6)$ & “ \\
\hline 10 & $79 / 9(7)$ & “ \\
\hline 11 & $51 / 4(7)$ & “ \\
\hline 12 & $26 / 5(4)$ & “ \\
\hline 13 & $8 / 10(1)$ & “" \\
\hline 14 & $66 / 4(8)$ & “ \\
\hline 15 & $54 / 12(2)$ & “ \\
\hline 16 & $26 / 8(4)$ & “ \\
\hline 17 & $8 / 11(2)$ & “ \\
\hline 18 & $8 / 11(5)$ & “" \\
\hline 19 & $12 / 5(3)$ & “ \\
\hline 20 & 28/7(4) & “ \\
\hline 21 & $20 / 4(8)$ & “ \\
\hline 22 & $63 / 2(2)$ & “ \\
\hline 23 & $91 / 8(2)$ & “ \\
\hline 24 & $91 / 8(6)$ & “ \\
\hline 25 & $20 / 8(7)$ & “ \\
\hline
\end{tabular}

A avaliação agronômica das plantas constou da medição da altura de planta (AP) e diâmetro da copa (DC), a qual foi realizada por três anos (2003, 2004 e 2005), e produção de frutos em dois anos (2004 e 2005). A produção de frutos foi avaliada com base em 29 colheitas realizadas de maio a novembro de 2004 e 26 colheitas em 2005, nos meses de fevereiro, março, junho, setembro e outubro. Dessa forma, a avaliação da produção nos 25 clones foi realizada por planta por colheita (Prod/PL/Col). Esses resultados foram analisados estatisticamente por Análise de Variância (ANOVA) com níveis de probabilidade de 1 e 5\% para o teste F. Em seguida, realizou-se a comparação de médias para as características altura de planta (AP), diâmetro de copa (DC) e produção por planta por colheita (Prod/PL/Col) por meio do teste de Scott-Knott.
Os frutos colhidos em 2004 e 2005 no estádio maduro foram transportados para o laboratório de Fisiologia e Tecnologia Pós-colheita da Embrapa Agroindústria Tropical em Fortaleza, CE, e avaliados quanto ao conteúdo de vitamina $\mathrm{C}$ por titulometria com solução de 2,6 diclorofenol-indofenol $0,02 \%$ de acordo com Strohecker e Henning (1967) e expresso em mg $100 \mathrm{~g}^{-1}$ de polpa em valores médios de três repetições e desvio padrão.

A atividade enzimática antioxidante foi avaliada no Laboratório de Bioquímica e Fisiologia de Frutos Tropicais da Universidade Federal do Ceará em frutos que foram mantidos à $-18^{\circ} \mathrm{C}$ até o momento das análises. A preparação do extrato bruto protéico iniciou com a homogeneização da polpa dos frutos congelados, seguida por diálise contra a água por $48 \mathrm{~h}$ e liofilização. As proteínas foram extraídas em tampão Fosfato monobásico de potássio $100 \mathrm{mM}$ com EDTA 0,1 mM, pH 7,0, em banho de gelo. A suspensão foi filtrada e centrifugada por $15 \mathrm{~min}$ à $12.000 \mathrm{~g} \mathrm{e} 4{ }^{\circ} \mathrm{C}$, o sobrenadante que constituía o extrato protéico foi separado, liofilizado (massa seca-MS) e armazenado a $-18{ }^{\circ} \mathrm{C}$. O conteúdo de proteínas solúveis totais foi avaliado de acordo com Bradford (1976) e expresso como a média de três repetições e desvio padrão.

A atividade da enzima antioxidante dismutase do superóxido (superoxide dismutase em inglês, SOD) foi determinada segundo Giannopolitis e Rieis (1977). Uma unidade de atividade (UA) foi definida como a quantidade de enzima necessária para inibir em $50 \%$ a fotorredução do NBT (sigla em inglês de nitroblue tetrazolium) e expressa como UA.g MS.min ${ }^{-1}$. A atividade da catalase (CAT) foi baseada no método de Beers e Sizer (1952). A atividade foi estimada pela medida do decréscimo na absorbância a $240 \mathrm{~nm}$ em intervalos de $30 \mathrm{~s}$, utilizandose o coeficiente de extinção molar de $\mathrm{H}_{2} \mathrm{O}_{2}$ de $36{\mathrm{M} . \mathrm{cm}^{-1}}^{-1}$ e expressa como $\mu \mathrm{mol} \mathrm{H}_{2} \mathrm{O}_{2}$.g MS $\min ^{-1}$. A atividade de peroxidase do ascorbato (ascorbate peroxidase em inglês, APX) nos extratos protéicos de acerola foi de acordo com a metodologia descrita por Nakano e Assada (1981). O decréscimo na leitura de absorbância a $290 \mathrm{~nm}$, medida em intervalos de $30 \mathrm{~s}$ foi mensurado como Índice de Oxidação do Ascorbato e a atividade foi expressa como $\mu \mathrm{mol} \mathrm{H}_{2} \mathrm{O}_{2}$.g MS.min ${ }^{-1}$. Todos os resultados de atividade das enzimas antioxidantes foram apresentados com o valor médio de três repetições e desvio padrão.

\section{RESULTADOS E DISCUSSÃO}

Na Tabela 2, são apresentados os quadrados médios das análises de variâncias, significâncias, médias e coeficientes de variação experimental para todas as características avaliadas em campo. Houve diferenças significativas entre clones para todos os caracteres 
avaliados nos três anos, exceto para altura de planta, que no primeiro ano não apresentou diferença significativa. Essas diferenças entre clones revelam uma condição favorável à seleção, considerando que parte dessa variação seja de natureza genética. Os coeficientes de variação experimental mantiveram-se em níveis aceitáveis para experimentação de campo com acerola (PAIVA et al., 2002).

Observando-se os valores mínimos e máximos dos caracteres altura de planta e diâmetro de copa dos clones nos três anos, as diferenças entre esses valores foram menores para a altura de planta em relação ao diâmetro da copa. Esse padrão de crescimento é resultado da seleção de plantas efetuadas entre e dentro de progênies no $1^{\circ}$ e $2^{\circ}$ ciclo (CORDEIRO et al., 2004), direcionadas para conformação de copa do tipo "guarda-chuva", isto é, a copa das plantas apresenta formatos que lembram este equipamento ou de "taça invertida". Essa é uma característica vantajosa em relação à copa tipo ereta, pois facilita a colheita dos frutos, sendo às vezes desnecessário efetuar as podas de formação (PAIVA et al., 2003b). Portanto, as características altura de planta e diâmetro de copa são utilizadas como indicadores da conformação tipo "guarda-chuva". Assim, procura-se selecionar plantas com menor porte e maior diâmetro de copa.

Tomando-se como referência o ano de 2005 e os valores das médias para AP e DC, observou-se uma variação de 1,75 a 2,50 m para AP, e de 2,44 a 3,70 m para DC (Tabela 3). Em comparação, os clones lançados pela Embrapa Agroindústria Tropical (PAIVA et al., 2003a) apresentaram altura de planta variando de 1,61 a 2,19 $\mathrm{m}$ e diâmetro de copa variando de 3,57 a 4,14 m, com valores próximos aos encontrados no presente trabalho.
Com relação à produção (Tabela. 2), observa-se que a produção média de frutos no segundo ano (2005), foi quatro vezes superior em relação ao primeiro ano, enquanto que a comparação do valor máximo mostra superioridade em seis vezes. Essas diferenças são mais evidentes quando se analisa a produção individual por clone (Tabela 3). Todavia, vale ressaltar que os valores encontrados são considerados baixos levando-se em consideração que o manejo ofertado incluiu irrigação e adubação e pelo fato de que produtividades acima de $100 \mathrm{~kg} /$ planta podem ser alcançadas com manejo semelhante. Isso evidencia a necessidade de avaliação dos clones por um período maior de tempo.

$\mathrm{Na}$ comparação de médias entre os 25 clones identificaram-se diferenças para as variáveis altura de planta e diâmetro de copa somente nos anos de 2004 e 2005, e para a variável produção, somente no ano de 2005 (Tabela. 3). Os clones que apresentaram maior Prod/PL/Col no ano de 2005 foram o clone 4 [79/10(9)], o 1 [23/2(3)] e o 21 [20/4(8)], e os que apresentaram menor produção foram o clones 20 [28/7(4)], 25 [20/8(7)] e 13 [8/10(1)]. Essa variável usada para avaliar produção fornece dados mais precisos uma vez que outras variáveis como produção por planta não informa o que realmente foi produzido por cada planta, pois uma parte dos frutos é perdida antes da realização da colheita. Com base na Prod/PL/Col o produtor pode estimar a produtividade do clone, considerando um determinado número de colheitas a serem realizadas no ano, programando as colheitas em função da demanda e da disponibilidade de mão-de-obra.

Além dos aspectos agronômicos, principalmente no que diz respeito à produção da cultura, o maior valor comercial

Tabela 2 - Quadrados médios das análises de variâncias e respectivas significâncias; médias, valores mínimos e máximos, e coeficientes de variação experimental (CV) para altura de planta (AP, metro) e diâmetro de copa (DC, metro) por três anos, e produção de frutos (Prod/PL/Col, kg) por dois anos para 25 clones de aceroleira

\begin{tabular}{lcllllllll}
\hline \multicolumn{1}{c}{ F.V. } & GL & \multicolumn{3}{c}{ AP } & \multicolumn{1}{c}{ DC } & \multicolumn{3}{c}{ PROD } \\
\hline ANO & & $(2003)$ & $(2004)$ & $(2005)$ & $(2003)$ & $(2004)$ & $(2005)$ & $(2004)$ & $(2005)$ \\
\hline Blocos & 2 & 0,9940 & 0,0124 & 0,0480 & 0,0475 & 0,2294 & 0,2425 & 0,0009 & 0,1884 \\
Clones & 24 & $0,0244^{\text {ns }}$ & $0,0477^{*}$ & $0,0375^{*}$ & $0,0627^{* *}$ & $0,1746^{*}$ & $0,1682^{*}$ & $0,0005^{*}$ & $0,0519^{*}$ \\
Resíduo & 48 & 0,0191 & 0,0219 & 0,0185 & 0,0251 & 0,0808 & 0,0773 & 0,0002 & 0,0263 \\
Média geral & - & 1,23 & 1,52 & 1,68 & 1,37 & 1,95 & 2,37 & 0,13 & 0,52 \\
Valor & - & 0,97 & 0,99 & 1,28 & 0,93 & 1,03 & 1,33 & 0,07 & 0,06 \\
mínimo & & & & & & & & & \\
Valor & - & 1,58 & 1,90 & 2,10 & 1,91 & 2,62 & 3,28 & 0,17 & 1,08 \\
máximo & - & 11,23 & 9,74 & 8,09 & 11,54 & 14,54 & 11,71 & 11,99 & 31,08 \\
CV $(\%)$ & - & & & & & & & &
\end{tabular}

${ }^{n s}$ não significativo; * $\mathrm{e} * *$ Significativos a $5 \%$ e $1 \%$ para o teste $\mathrm{F}$, respectivamente 
dos frutos da aceroleira está relacionado ao seu conteúdo de vitamina $\mathrm{C}$ devido à sua propriedade antioxidante. Em relação a esse parâmetro antioxidante, os conteúdos de vitamina C (Figura 1) encontrados no presente trabalho variaram entre 744,5 (clone 20/4(8)) e 1.434,8 mg $100 \mathrm{~g}^{-1}$ (clone 8/10(1)). Apesar do clone 8/10(1) apresentar elevado conteúdo de vitamina $\mathrm{C}$, este material apresentou baixa produção quando comparado aos outros clones (Tabela 3). Por isso, os trabalhos de melhoramento genético dessa cultura devem ter como objetivos a obtenção de materiais com alta produção e elevado conteúdo de vitamina C.

A vitamina $\mathrm{C}$ é o termo genérico para todos os compostos que apresentam a atividade biológica do ácido
L-ascórbico e está como a mais importante para a nutrição humana, pois auxilia na manutenção da saúde da pele, gengiva e dos vasos sanguíneos (LEE; KADER, 2000). A ação antioxidante do ácido ascórbico se deve a sua reação direta de neutralização de radicais livres como superóxido (auto-oxidação) ou sendo doador de elétrons para o peróxido de hidrogênio em reação catalisada pela enzima peroxidase do ascorbato (LURIE, 2003). O conteúdo de vitamina C pode variar dentre variedades de uma mesma espécie, como exemplo, as cultivares de aceroleira lançadas em 2003, pela EMBRAPA apresentaram conteúdos de vitamina C variando entre 1.000 e $1.800 \mathrm{mg} 100 \mathrm{~g}^{-1}$ (PAIVA et al., 2003a), ou ainda dentre os tecidos de um mesmo órgão,

Tabela 3 - Comparação de médias para as características altura de planta (AP), diâmetro de copa (DC) e produção por planta por colheita (Prod/PL/Col) dos 25 clones de aceroleira de segundo ciclo no período de 2003 a 2005

\begin{tabular}{|c|c|c|c|c|c|c|c|c|}
\hline \multirow{2}{*}{ Clones } & \multicolumn{3}{|c|}{$\mathrm{AP}(\mathrm{m})$} & \multicolumn{3}{|c|}{$\mathrm{DC}(\mathrm{m})$} & \multicolumn{2}{|c|}{ Prod/PL/Col (kg) } \\
\hline & 2003 & 2004 & 2005 & 2003 & 2004 & 2005 & 2004 & 2005 \\
\hline $23 / 2(3)$ & $1,24 \mathrm{a}^{*}$ & $1,74 \mathrm{a}$ & $2,26 \mathrm{a}$ & $1,20 \mathrm{a}$ & $2,32 \mathrm{~b}$ & $3,20 \mathrm{a}$ & $0,18 \mathrm{a}$ & $0,83 \mathrm{a}$ \\
\hline 68/1(9) & $1,37 \mathrm{a}$ & $1,81 \mathrm{a}$ & $2,24 \mathrm{a}$ & $1,32 \mathrm{a}$ & $2,63 \mathrm{a}$ & $3,61 \mathrm{a}$ & $0,18 \mathrm{a}$ & $0,55 \mathrm{~b}$ \\
\hline $75 / 2(7)$ & $1,24 \mathrm{a}$ & $1,65 \mathrm{~b}$ & $2,37 \mathrm{a}$ & $1,20 \mathrm{a}$ & $2,37 \mathrm{~b}$ & $3,50 \mathrm{a}$ & $0,18 \mathrm{a}$ & $0,64 \mathrm{a}$ \\
\hline 79/10(9) & $1,45 \mathrm{a}$ & $1,87 \mathrm{a}$ & $2,50 \mathrm{a}$ & $1,34 \mathrm{a}$ & $2,66 \mathrm{a}$ & $3,11 \mathrm{a}$ & $0,16 \mathrm{a}$ & $0,84 \mathrm{a}$ \\
\hline $8 / 2(3)$ & $1,26 \mathrm{a}$ & $1,57 \mathrm{~b}$ & $1,86 \mathrm{~b}$ & $1,39 \mathrm{a}$ & $2,30 \mathrm{~b}$ & $2,84 \mathrm{~b}$ & $0,14 \mathrm{a}$ & $0,52 \mathrm{~b}$ \\
\hline 87/11(7) & $1,28 \mathrm{a}$ & $1,46 \mathrm{~b}$ & $1,75 \mathrm{~b}$ & $1,34 \mathrm{a}$ & $2,08 \mathrm{~b}$ & $2,44 \mathrm{~b}$ & $0,15 \mathrm{a}$ & $0,44 \mathrm{~b}$ \\
\hline $66 / 7(5)$ & $1,24 \mathrm{a}$ & $1,62 \mathrm{~b}$ & $2,10 \mathrm{~b}$ & $1,56 \mathrm{a}$ & $2,30 \mathrm{~b}$ & $3,30 \mathrm{a}$ & $0,16 \mathrm{a}$ & $0,69 \mathrm{a}$ \\
\hline $66 / 7(6)$ & $1,32 \mathrm{a}$ & $1,68 \mathrm{~b}$ & $2,10 \mathrm{~b}$ & $1,51 \mathrm{a}$ & $2,37 \mathrm{~b}$ & $3,39 \mathrm{a}$ & $0,19 \mathrm{a}$ & $0,40 \mathrm{~b}$ \\
\hline 79/9(6) & $1,17 \mathrm{a}$ & $1,48 \mathrm{~b}$ & $1,91 \mathrm{~b}$ & $1,40 \mathrm{a}$ & $2,08 \mathrm{~b}$ & $2,47 \mathrm{~b}$ & $0,15 \mathrm{a}$ & $0,65 \mathrm{a}$ \\
\hline $79 / 9(7)$ & $1,27 \mathrm{a}$ & $1,72 \mathrm{a}$ & $2,18 \mathrm{a}$ & $1,36 \mathrm{a}$ & $2,33 \mathrm{~b}$ & $3,34 \mathrm{a}$ & $0,17 \mathrm{a}$ & $0,52 \mathrm{~b}$ \\
\hline $51 / 4(7)$ & $1,02 \mathrm{a}$ & $1,67 \mathrm{~b}$ & $2,47 \mathrm{a}$ & $1,21 \mathrm{a}$ & $2,45 \mathrm{~b}$ & $3,67 \mathrm{a}$ & $0,18 \mathrm{a}$ & $0,48 \mathrm{~b}$ \\
\hline $26 / 5(4)$ & $1,32 \mathrm{a}$ & $1,79 \mathrm{a}$ & $2,18 \mathrm{a}$ & $1,26 \mathrm{a}$ & $2,25 \mathrm{~b}$ & $3,21 \mathrm{a}$ & $0,17 \mathrm{a}$ & $0,67 \mathrm{a}$ \\
\hline $8 / 10(1)$ & $1,08 \mathrm{a}$ & $1,67 \mathrm{~b}$ & $2,06 \mathrm{~b}$ & $1,19 \mathrm{a}$ & $2,36 \mathrm{~b}$ & $3,19 \mathrm{a}$ & $0,16 \mathrm{a}$ & $0,38 \mathrm{~b}$ \\
\hline $66 / 4(8)$ & $1,17 \mathrm{a}$ & $1,64 \mathrm{~b}$ & $2,22 \mathrm{a}$ & $1,24 \mathrm{a}$ & $2,29 \mathrm{~b}$ & $2,81 \mathrm{~b}$ & $0,15 \mathrm{a}$ & $0,39 \mathrm{~b}$ \\
\hline $54 / 12(2)$ & $1,20 \mathrm{a}$ & $1,75 \mathrm{a}$ & $2,37 \mathrm{a}$ & $1,39 \mathrm{a}$ & $2,24 \mathrm{~b}$ & $3,14 \mathrm{a}$ & $0,18 \mathrm{a}$ & $0,39 \mathrm{~b}$ \\
\hline $26 / 8(4)$ & $1,26 \mathrm{a}$ & $1,89 \mathrm{a}$ & $2,48 \mathrm{a}$ & $1,48 \mathrm{a}$ & $2,72 \mathrm{a}$ & $3,70 \mathrm{a}$ & $0,17 \mathrm{a}$ & $0,49 \mathrm{~b}$ \\
\hline $8 / 11(2)$ & $1,08 \mathrm{a}$ & $1,57 \mathrm{~b}$ & $2,00 \mathrm{~b}$ & $1,16 \mathrm{a}$ & $2,15 \mathrm{~b}$ & $2,74 \mathrm{~b}$ & $0,14 \mathrm{a}$ & $0,49 \mathrm{~b}$ \\
\hline $8 / 11(5)$ & $1,27 \mathrm{a}$ & $1,60 \mathrm{~b}$ & $1,98 \mathrm{~b}$ & $1,42 \mathrm{a}$ & $2,23 \mathrm{~b}$ & $2,67 \mathrm{~b}$ & $0,15 \mathrm{a}$ & $0,49 \mathrm{~b}$ \\
\hline $12 / 5(3)$ & $1,10 \mathrm{a}$ & $1,76 \mathrm{a}$ & $2,39 \mathrm{a}$ & $1,20 \mathrm{a}$ & $2,93 \mathrm{a}$ & $3,58 \mathrm{a}$ & $0,19 \mathrm{a}$ & $0,48 \mathrm{~b}$ \\
\hline $28 / 7(4)$ & $1,09 \mathrm{a}$ & $1,56 \mathrm{~b}$ & $2,09 \mathrm{~b}$ & $1,12 \mathrm{a}$ & $2,48 \mathrm{~b}$ & $3,22 \mathrm{a}$ & $0,18 \mathrm{a}$ & $0,27 \mathrm{~b}$ \\
\hline $20 / 4(8)$ & $1,13 \mathrm{a}$ & $1,72 \mathrm{a}$ & $2,19 \mathrm{a}$ & $1,55 \mathrm{a}$ & $2,46 \mathrm{~b}$ & $3,41 \mathrm{a}$ & $0,17 \mathrm{a}$ & $0,70 \mathrm{a}$ \\
\hline $63 / 2(2)$ & $1,09 \mathrm{a}$ & $1,82 \mathrm{a}$ & $2,37 \mathrm{a}$ & $1,36 \mathrm{a}$ & $2,82 \mathrm{a}$ & $3,04 \mathrm{~b}$ & $0,16 \mathrm{a}$ & $0,49 \mathrm{~b}$ \\
\hline $91 / 8(2)$ & $1,26 \mathrm{a}$ & $1,75 \mathrm{a}$ & $2,29 \mathrm{a}$ & $1,50 \mathrm{a}$ & $1,93 \mathrm{~b}$ & $2,88 \mathrm{~b}$ & $0,16 \mathrm{a}$ & $0,48 \mathrm{~b}$ \\
\hline $91 / 8(6)$ & $1,23 \mathrm{a}$ & $1,58 \mathrm{~b}$ & $1,97 \mathrm{~b}$ & $1,68 \mathrm{a}$ & $2,17 \mathrm{~b}$ & $2,97 \mathrm{~b}$ & $0,16 \mathrm{a}$ & $0,47 \mathrm{~b}$ \\
\hline $20 / 8(7)$ & $1,16 \mathrm{a}$ & $1,64 \mathrm{~b}$ & $2,13 \mathrm{~b}$ & $1,22 \mathrm{a}$ & $2,43 \mathrm{~b}$ & $3,20 \mathrm{a}$ & $0,16 \mathrm{a}$ & $0,31 \mathrm{~b}$ \\
\hline Média geral & 1,23 & 1,52 & 1,68 & 1,37 & 1,95 & 2,37 & 0,13 & 0,52 \\
\hline
\end{tabular}

*Clones seguidos pelas mesmas letras não diferem entre si ao nível de 5\% pelo teste de Scott-Knott 
como no caso da maçã que apresenta a maior concentração de vitamina C total na casca (LI et al., 2008).

De modo geral, os frutos não são boas fontes de proteína para dieta humana, diferentemente das sementes que acumulam grandes quantidades de proteínas de reserva (CHITARRA; CHITARRA, 2005). A Figura 2 apresenta o conteúdo de proteínas totais nos 25 clones analisados e este variou de 2,25 (clone 91/8(6)) a 7,53 mg g MS ${ }^{-1}$ (clone 79/10(9)). Uma parte considerável das proteínas encontradas nos frutos tem papel metabólico importante como é o caso das enzimas.

O amadurecimento e a senescência de frutos são considerados fenômenos oxidativos e as principais espécies reativas de oxigênio envolvidas com os danos oxidativos são: superóxido $\left(\mathrm{O}_{2}^{*}\right)$, peróxido de hidrogênio $\left(\mathrm{H}_{2} \mathrm{O}_{2}\right)$, radical hidroxi $\left(\mathrm{OH}^{*}\right)$, radical peroxi $\left(\mathrm{ROO}^{*}\right)$, radical alcoxi (RO') e oxigênio singlet $\left({ }^{\mid} \mathrm{O}_{2}\right)$ (BHATTACHARJEE, 2005). A SOD é uma enzima antioxidante responsável pela dismutação do radical superóxido $\left(\mathrm{O}_{2}\right)$ em peróxido de hidrogênio $\left(\mathrm{H}_{2} \mathrm{O}_{2}\right)$, o qual pode ser eliminado tanto pela CAT sendo transformado em água e $\mathrm{O}_{2}$ ou pela APX que utiliza o ácido ascórbico (vitamina $\mathrm{C}$ ) como doador de hidrogênio. A atividade da SOD variou de 57,48 a 688,21

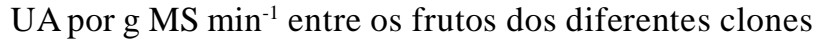

de aceroleira (Figura 3). Os clones 79/10(9) e 20/8(7) se destacaram com os mais altos valores médios de atividades com 669,94 e 688,21 UA por $\mathrm{g} \mathrm{MS} \mathrm{min}^{-1}$, respectivamente, enquanto que os clones 8/2(3) e 28/7(4) apresentaram os mais baixos com 60,78 e 57,48 UA por $\mathrm{g} \mathrm{MS} \mathrm{min}^{-1}$, respectivamente.

As atividades das enzimas APX e CAT podem ser observadas na Figura 4. A atividade da CAT variou muito entre os 25 clones, sendo o maior valor médio de atividade encontrado no clone 8/10(1) com 67,29 $\mu \mathrm{mol}$ $\mathrm{H}_{2} \mathrm{O}_{2}$ por $\mathrm{g} \mathrm{MS} \mathrm{min}^{-1}$ e o menor no clone 26/5(4) com 1,85 $\mu \mathrm{mol} \mu \mathrm{H}_{2} \mathrm{O}_{2}$ por g MS min ${ }^{-1}$. A atividade média da APX foi bem mais baixa do que a da CAT, levando em conta que a atividade de ambas se baseia na capacidade de reduzir o $\mathrm{H}_{2} \mathrm{O}_{2}$. O maior valor médio de atividade da APX foi 0,097 $\mu \mathrm{mol}$ $\mathrm{H}_{2} \mathrm{O}_{2}$ por $\mathrm{g} \mathrm{MS} \mathrm{min}^{-1}$ encontrada no clone 75/2(7) e a menor foi $0,0074 \mu \mathrm{mol} \mathrm{H}_{2} \mathrm{O}_{2}$ por $\mathrm{g}$ MS $\min ^{-1}$ no clone $79 / 9(7)$. A baixa atividade da peroxidase do ascorbato indica que esta não é a principal rota enzimática de eliminação do $\mathrm{H}_{2} \mathrm{O}_{2}$ produzido pela SOD na acerola, apesar do seu alto conteúdo de vitamina $\mathrm{C}$ total. Portanto, nesses clones de acerola, a CAT se mostra como a maior responsável pela redução do $\mathrm{H}_{2} \mathrm{O}_{2}$ em $\mathrm{H}_{2} \mathrm{O}$ e $\mathrm{O}_{2}$ e o alto conteúdo de vitamina $\mathrm{C}$ pode ter uma função antioxidante própria, independente da ação da APX.

Figura 1 - Conteúdo de vitamina $\mathrm{C}$ encontrado em frutos de 25 clones de aceroleira representado pelos valores médios e respectivos desvios padrão

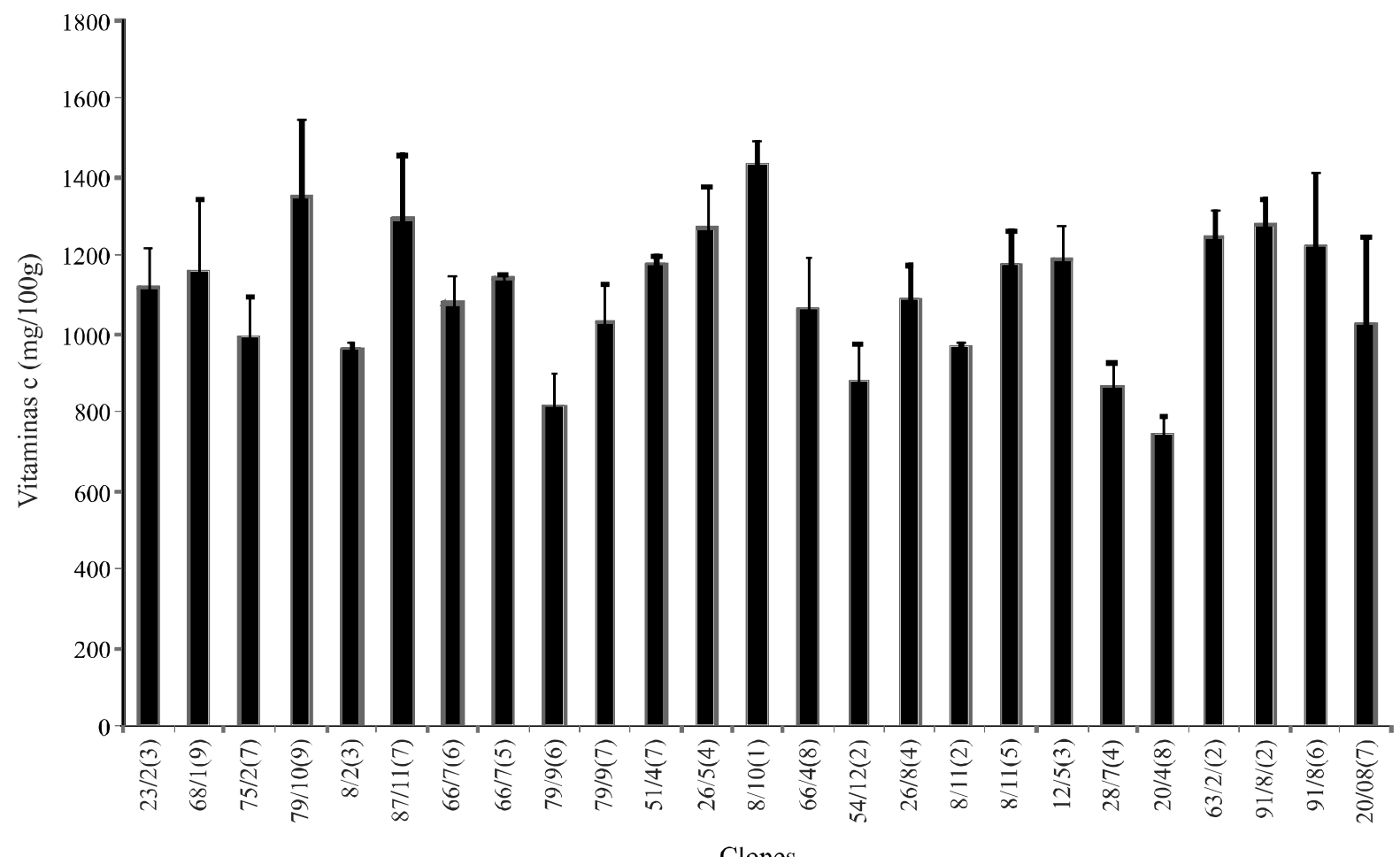


Figura 2 - Conteúdo protéico dos frutos de 25 clones de aceroleira representado pelos valores médios e respectivos desvios padrão

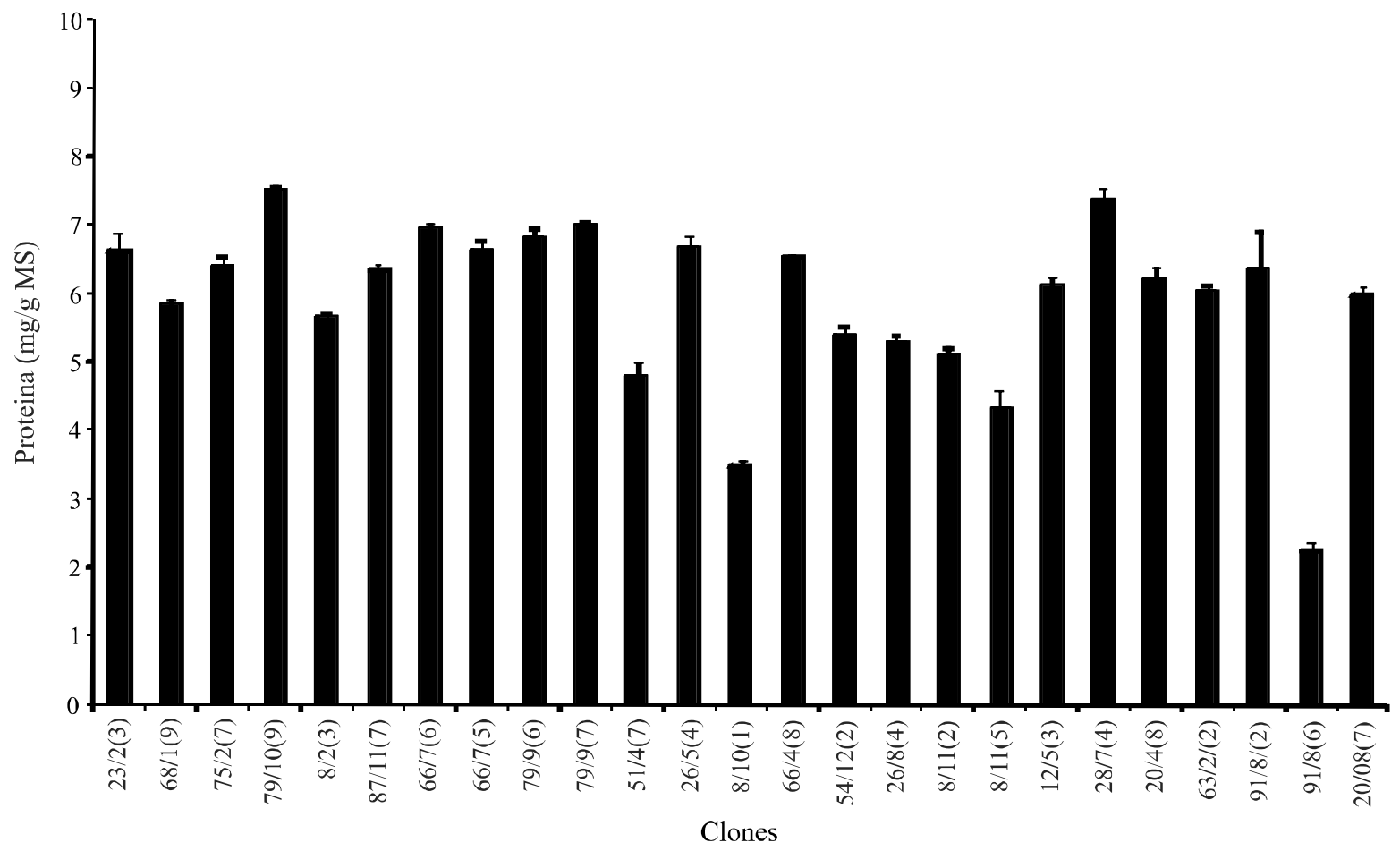

Figura 3 - Atividade da enzima dismutase do superóxido (SOD) em frutos de 25 clones de aceroleira representado pelos valores médios e respectivos desvios padrão

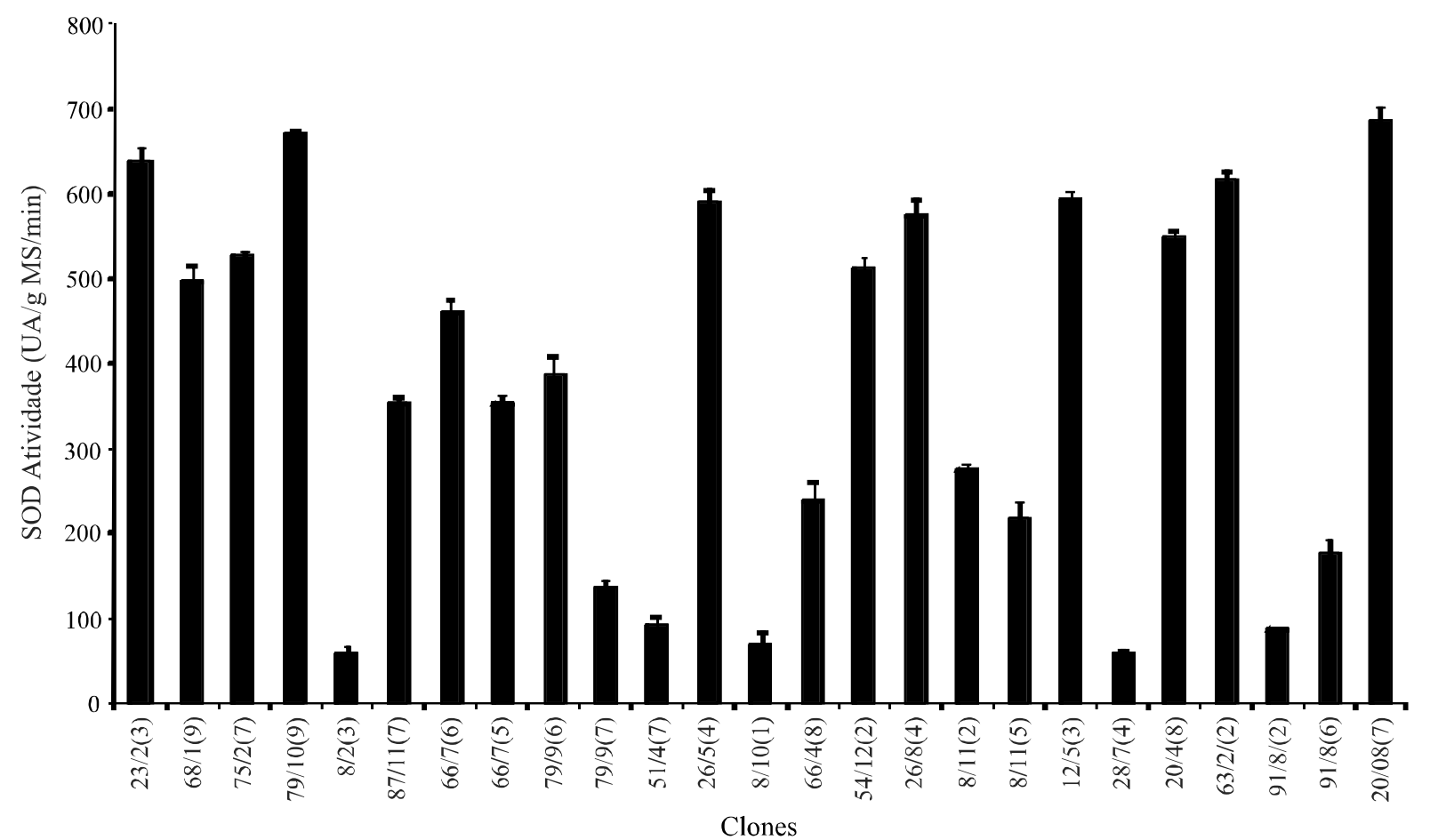


Figura 4 - Atividade das enzimas peroxidase do ascorbato (APX) e catalase (CAT) de frutos de 25 clones de aceroleira representado pelos valores médios e respectivos desvios padrão

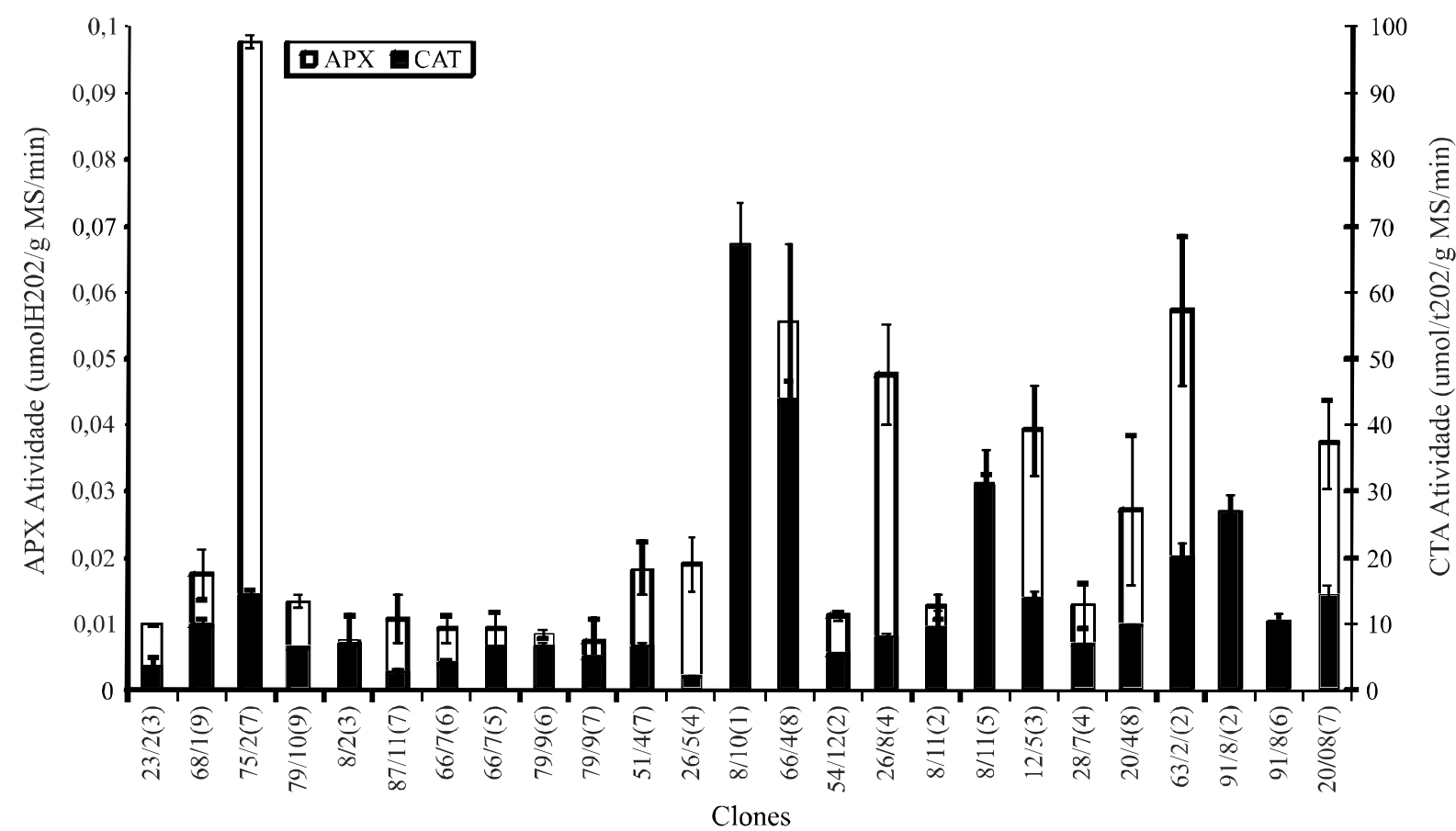

A atividade das enzimas antioxidantes tem sido associada a mudanças relacionadas com o estádio de desenvolvimento de frutos. Wang e Jiao (2001) observaram que durante o amadurecimento e senescência de amorapreta tanto a atividade das enzimas SOD, CAT, APX como o conteúdo de antioxidantes não enzimáticos como ácido ascórbico decresciam levando a um desequilíbrio oxidativo que resultava em danos às membranas biológicas e a integridade dos tecidos do fruto, característicos dessas etapas do desenvolvimento. Assim, os mesmos autores postularam que frutos com melhores sistemas enzimáticos antioxidantes apresentavam uma redução nos danos às membranas o que estava relacionado com maiores períodos de conservação pós-colheita devido a retardos na senescência.

Os resultados obtidos nos clones estudados indicam que a SOD é a mais ativa dentre as enzimas avaliadas, apesar desses frutos terem apresentado atividades enzimáticas relativamente baixas quando comparadas a outros frutos como a amora-preta (WANG; JIAO, 2001) e mangas (WANG et al., 2008).

O clone 8/10(1) apresentou um alto conteúdo de vitamina $\mathrm{C}$ total e de atividade da CAT, embora uma baixa atividade da SOD. Já o clone 79/10(9) apresentou uma alta atividade da SOD e alto conteúdo de vitamina C, apesar da baixa atividade da CAT e da APX. Esses resultados indicam que o alto conteúdo de vitamina $\mathrm{C}$ está associado à alta atividade enzimática antioxidante através de eliminação do radical superóxido pela SOD diminuindo a auto-oxidação da vitamina $\mathrm{C}$ ou da neutralização do radical peróxido pela CAT.

De acordo com Paiva et al. (2003b), na fruticultura moderna é preciso que a produção seja compensadora e a qualidade dos frutos, uniforme, sendo esses padrões alcançados com o uso de clones. Considerando a acerola uma cultura perene, a produção de clones permite a disponibilização mais rápida de materiais com características superiores e mais uniformes para a comercialização.

\section{CONCLUSÕES}

1. Dentre todos os materiais estudados, os 23/2(3), 79/10(9) e 26/5(4) apresentam uma alta produtividade, altura e diâmetro satisfatórios para o formato "guardachuva", bons índices de conteúdo protéico, de vitamina $\mathrm{C}$ e de atividade da enzima SOD demonstrando um bom potencial, principalmente para a indústria de extração de vitamina $C$. No entanto, todos esses materiais não apresentaram as mesmas vantagens quanto ao desenvolvimento vegetativo, requerendo uma maior atenção em estudos futuros antes de poderem ser definitivamente lançados como clones e recomendados para produtores agrícolas; 
2. Apesar das diferenças estatisticamente insignificantes, o material 20/4(8) se apresenta como um dos mais produtivos, com um porte pequeno, maior diâmetro de copa e boa atividade enzimática antioxidante, apesar do mais baixo conteúdo de vitamina $C$. Essas características podem ser benéficas para a produção voltada para o consumo in natura de acerola.

\section{AGRADECIMENTOS}

Ao INCT - Frutos Tropicais/CNPq e à FUNCAP, pelo suporte financeiro e pela concessão de bolsas para a realização deste trabalho e à Embrapa Agroindústria Tropical, pela permissão de uso e condução do trabalho em sua estação experimental.

\section{REFERÊNCIAS}

AGUIAR, M. J. N. et al. Dados climatológicos: estação de Pacajús. Fortaleza: Embrapa Agroindústria Tropical, 2002. 26 p.

ARAÚJO, C. L. et al. Biological activity of proteins from pulps of tropical fruits. Food Chemistry, v. 85, n. 01, p. 107110, 2004.

BEERS-JR, R. F.; SIZER, I. W. A spectrofotometric method for measuring the breakdown of hydrogen peroxide by catalase. Journal of Biological Chemistry, v. 195, n. 01, p. 133-140, 1952

BHATTACHARJEE, S. Reactive oxygen species and oxidative burst: roles in stress, senescence and signal transduction in plants. Current Science, v. 89, n. 07, p. 1113-1121. 2005.

BRADFORD, M. M. A rapid and sensitive method for the quantification of micrograms quantities of protein utilizing the principle of protein dye-binding. Analitical Biochemistry, v. 72, p. 246-254, 1976.

Chitarra, M. I. F.; CHITARrRA, A. B. Pós-colheita de frutos e hortaliças fisiologia e manuseio. 2. ed. , Lavras-MG: ESAL, 2005. 783 p.

CORDEIRO, E. R. et al. Avaliação de progênies e estimação de parâmetros genéticos de aceroleira. Revista Ciência Agronômica, v. 35, n. 02, p. 349-354, 2004.

GIANNOPOLITIS, C. N., RIES, S. K. Superoxides Dismutases. I. Ocurrences in highter plants. Plant Physiology, v. 59, p. 309-314, 1977.
KULKARNI, A. P.; ARADHYA, S. M. Chemical changes and antioxidant activity in pomegranate arils during fruit development. Food Chemistry, v. 93, n. 02, p. 319-324, 2005.

LEE, S. K.; KADER, A. A. Preharvest and postharvest factors influencing vitamin $\mathrm{C}$ content of horticultural crops. Postharvest Biology and Technology, v. 20, n. 03, p. 207-220, 2000.

LEJA, M.; MARECZEK, A.; BEN, J. Antioxidant properties of two apple cultivars during long-term storage. Food Chemistry, v. 80 , n. 03 , p. 303-307, 2003.

LI, M. J. et al. Distribution and metabolism of ascorbic acid in apple fruits (Malus domestica Borkh cv. Gala). Plant Science, v. 174, n. 06, p. 606-612, 2008.

LURIE, S. Antioxidants. In: HODGES, D. M. Postharvest oxidative stress in horticultural crops. Food Product Press, Binghampton-NY, 2003. p. 131-150.

NAKANO, Y.; ASADA, K. Hydrogen peroxide is scavenged by ascorbate-specific peroxidases in spinach chloroplasts. Plant Cell Physiology, v. 22, n. 05, p. 867-880. 1981.

OLSSON M. E. et al. Antioxidant levels and inhibition of cancer cell proliferation in vitro by extracts from organically and conventionally cultivated strawberries. Journal of Agricultural and Food Chemistry, v. 54, n. 04, p. 12481255. 2006.

PAIVA, J. R. et al. Genetic progress of selections between and within 'Caribbean' cherry open pollination progenies. Crop Breeding and Applied Biotechnology, v. 02, n. 02, p. 299-306, 2002.

PAIVA, J. R. et al. Clones de Aceroleira: BRS 235 ou Apodi, BRS 236 ou Cereja, BRS 237 ou Roxinha e BRS 238 ou Frutacor. Fortaleza: Embrapa Agroindústria Tropical. 2003a. 3p. (Comunicado Técnico, 87).

PAIVA, J. R. et al. Seleção preliminar de clones de aceroleira no estado do Ceará. Ciência e Agrotecnologia, v. 27, n. 05, p. $1038-1044,2003$ b.

STROHECKER, R.; HENNING, H. M. Analisis de vitaminas: métodos comprobados. Madrid: Paz Montalvo, 1967. 428 p.

WANG, S. Y.; JIAO, H. Changes in oxygen-scavenging systems and membrane lipid peroxidation during maturation and ripening in blackberry. Journal Agriculture and Food Chemistry, v. 49, n. 03, p. 1612-1619, 2001.

WANG, B. et al. Reduced chilling injury in mango fruit by 2,4-dichlorophenoxyacetic acid and the antioxidant response. Postharvest Biology and Technology, v. 48, n. 02, p. 172-181, 2008. 